\title{
A COOPERAÇÃO SUL-SUL BRASILEIRA COM A ÁFRICA NO CAMPO DA ALIMENTAÇÃO: uma política coerente com o desenvolvimento ? $^{1}$
}

\author{
Enara Echart Muñoz* \\ Tássia Camila de Oliveira Carvalho* *
}

\begin{abstract}
O Brasil participa ativamente da cooperação internacional para o desenvolvimento em áreas muito diversas, mas com especial ênfase na agricultura e na alimentação. Nesse campo, o Brasil se apresenta como uma referência internacional devido ao relativo êxito de programas internos (Bolsa Família, Fome Zero, etc.) e à possibilidade de transferência externa dessas experiências. Por outro lado, trata-se de um setor-chave para as empresas brasileiras, que têm, no agronegócio, uma das bases de sua acumulação de capital. A alimentação é assim, ao mesmo tempo, um direito básico, que deve ser garantido e protegido, e uma mercadoria que pode ser trocada com alto lucro no mercado de commodities. As tensões geradas em torno dessas duas visões são as que motivam este artigo, que pretende analisar as práticas de Cooperação Sul-Sul do Brasil com os países africanos no campo da alimentação, a partir de um enfoque de coerência de políticas com o desenvolvimento.

PALAvraS-CHAvE: Cooperação Sul-Sul. Brasil. África. Alimentação. Coerência de Políticas.
\end{abstract}

\section{INTRODUÇÃO: cooperação Sul-Sul e coerência de políticas com o de- senvolvimento}

As relações do Brasil com o continente africano se intensificaram na última década em âmbitos bem diversos. A estratégia Sul-Sul ganhou destaque como forma de diversificar a política externa brasileira, colocando a África no mapa da diplomacia brasileira: aumentaram as viagens oficiais à região (o Presidente Lula visitou o continente em 34 ocasióes, enquanto Fernando Henrique Cardoso foi apenas quatro

\footnotetext{
* Universidade Federal do Estado do Rio de Janeiro. Escola de Ciência Política - CCJP / UNIRIO.

Rua Voluntários da Pátria, 107. Cep: 22270-000. Botafogo - Rio de Janeiro - Rio de Janeiro - Brasil. enara.munoz@ unirio.br

** Universidade Estadual do Rio de Janeiro.

Rua da Matriz, 82. Cep: 22260-100. Botafogo -Rio de Janeiro - Rio de Janeiro - Brasil. tassiaurio@gmail.com

${ }^{1} \mathrm{~A}$ pesquisa que deu origem a este artigo foi financiada pelo projeto do CNPQ: "A cooperação Sul-Sul brasileira com Moçambique, Guiné-Bissau e Senegal: discursos, práticas e percepções no campo da alimentação" (Chamada MCTI/CNPq/MEC/CAPES No 43/2013). Queremos agradecer ao GRISUL (Grupo de Relações Internacionais e Sul Global da Escola de Ciência Política da UNIRIO) a colaboração na pesquisa de dados e particularmente a Bruna Soares de Aguiar, Joana Serafim da Silva, Henrique Fonseca Correia, Lucas Gomes de Almeida, Natália Pasetti e Roger Lucas Correa Martins.
}

vezes) e se abriram novas embaixadas (tornando-se o Brasil, com 38 embaixadas, o quarto país com maior presença diplomática no continente). Também cresceram exponencialmente as relações comerciais (de U\$ 4 bilhões em 2000 para U\$ 20 bilhões em 2010) e os investimentos diretos na região, acompanhados de um movimento de internacionalização das empresas brasileiras (25 delas estão presentes em 30 países africanos) (Vieitas e Aboim, 2013). A região, ademais, tornou-se estratégica no campo da defesa, como parte do Atlântico Sul. Já no âmbito da Cooperação Sul-Sul (CSS), intensificaram-se também as parcerias em saúde, educação e alimentação - as três principais áreas de atuação da CSS brasileira.

A alimentação merece um destaque especial. Se, por um lado, o Brasil se apresenta como uma referência internacional devido ao relativo êxito de programas internos (como o Bolsa Família e o Fome Zero) e à possibilidade de transferência externa dessas experiências, por outro, a alimentação é um setor-chave para as empresas brasileiras, que têm no agronegócio uma das bases da sua acumulação de capital. A alimentação é, assim, ao mesmo tempo, 
um direito básico que deve ser garantido e protegido, e uma mercadoria que pode ser trocada com alto lucro no mercado de commodities. As tensões geradas em torno dessas duas visões e, em termos mais amplos, em torno do debate sobre modelos de desenvolvimento, são as que motivam este artigo.

Diante dos que defendem uma complementaridade, preocupa-nos o fato de que, apesar das altas taxas de crescimento na África (em torno de $5 \%$ para a região como conjunto, com destaque para países como Sudão do Sul, Libéria ou Etiopia), a proporção de pessoas em situação de pobreza ainda é altíssima: quase a metade dos africanos continua vivendo com menos de 1,25 dólares por dia. Esse fato nos leva a pensar nas contradições existentes entre visões sobre o desenvolvimento: como aumento de oportunidades e liberdades das pessoas, como defendia Amartya Sen (2000), ou do setor privado, como sustentam as teorias da modernização, ou ainda como garantia e ampliação dos direitos humanos, proposta do enfoque baseado nos Direitos Humanos do Programa de Nações Unidas para o Desenvolvimento (OCNUDH, 2006; Echart et al, 2013).

Este artigo pretende mostrar essas tensões entre os atores e práticas em disputa, para entender o lugar que ocupa a Cooperação SulSul brasileira nesse ambiente. Para essa análi? se, o texto se propõe a um enfoque sistêmico, ᄂ. segundo o qual a política externa dos Estados (e, portanto, a CSS como parte dela) não pode s. กิ transnacionais que atravessam esses Estados, mem da ordem mundial na qual tais atores estão í inseridos. Essa ordem e, dentro dela, o sistema \& internacional de cooperação para o desenvol今े vimento, são aqui entendidos não só como um $\overrightarrow{~ c o n j u n t o ~ d e ~ a t o r e s, ~ n o r m a s ~ e ~ i n s t i t u i c ̧ o ̃ e s, ~ m a s ~}$ também como um sistema de legitimação da hegemonia de determinados atores e marcos discursivos (Cox, 1996; Escobar, 1996).

Nesse cenário, é preciso ter em conta não só a posição sistêmica dos Estados (no centro ou na periferia do sistema-mundo) para analisar as relações da CSS, mas também as estrategias de extraversão que existem dentro da periferia e que permitem a determinados atores internos (principalmente as elites políticas e econômicas) incrementarem o seu poder às expensas de outros (Bayart, 2011). Para Bayart

\footnotetext{
cada vez mais atores privados estrangeiros estão presentes na África exclusivamente com fins de lucro, e têm se tornado parceiros essenciais nas estrategias de extraversão implementadas por aqueles que detêm o poder em cada região (Bayart, 2011, p 54).
}

Se a CSS não tiver em conta essas relações de poder, terminará fortalecendo essas práticas de acumulação econômica em detrimento das populações, incrementando, com isso, os sistemas de desigualdade e de dominação interna. Olhar para o complexo Estado/mercado/ sociedade e as disputas estabelecidas entre eles em torno do desenvolvimento ajuda a visibilizar o papel crescente das associações público -privadas nesse cenário e a exclusão dos atores sociais que questionam o modelo de desenvolvimento dominante.

A partir dessa aproximação, guiamo-nos por um enfoque de coerência de políticas com o desenvolvimento (e com as diversas narrativas em torno desse desenvolvimento). A hipótese que guia este trabalho é a de que existem fortes incoerências nas atuações em prol do desenvolvimento, o que pode, em certas ocasiões, se converter em práticas de anticooperação (Llistar, 2009). Não se trata só de questionar, como costuma ser habitual, as incoerências entre o discurso e as práticas por parte dos governos, mas também entre os discursos que se mantêm diante dos diversos atores e das práticas desenvolvidas nos diversos espaços. Trata-se de uma coerência de políticas em suas dimensões vertical (entre o discurso e a prática), horizontal (entre todas as políticas que podem incidir no desenvolvimento dos países parceiros), temporal (em longo prazo) e global (no cenário internacional), para construir uma ação coletiva concertada (Millán, 2014).

A coerência vertical é aquela que com- 
para o discurso e a prática, os objetivos (no caso o desenvolvimento) e as ações para atingir esses objetivos (os projetos de CSS). A cooperação brasileira para o desenvolvimento é definida como

[...] a totalidade de recursos investidos pelo governo federal brasileiro, totalmente a fundo perdido, no governo de outros países, em nacionais de outros países em território brasileiro, ou em organizações internacionais com o propósito de contribuir para o desenvolvimento internacional, entendido como o fortalecimento das capacidades de organizações internacionais e de grupos ou populações de outros países para a melhoria de suas condições socioeconômica. (IPEA, 2010, p 17).

Trata-se de comprovar se os projetos de cooperação implementados contribuem para esse propósito. Ainda no caso da alimentação, importa analisar a coerência entre seu reconhecimento como um direito humano na legislação brasileira (o que implica uma serie de obrigações para o Estado, inclusive na sua ação exterior) e o apoio a práticas que podem colocar esse direito em perigo.

Em relação à coerência horizontal, ela implica olhar para todas as políticas públicas que podem ter incidência nos processos de desenvolvimento dos países parceiros. Para isso, a CSS não pode ser entendida isoladamente do resto das políticas (externa, comercial, de defesa, de assinatura de acordos de investimento, de apoio ao agrobussiness e à internacionalização de empresas brasileiras, etc). Pelo contrario, é importante ver as possiveis incoerências entre as diversas ações, assim como entender que tipo de práticas é privilegiado, quais as que recebem o grosso dos recursos, as que têm um maior impacto em termos de desenvolvimento, etc.

A coêrencia temporal entende o desenvolvimento como um processo de longo prazo, o que exige que as ações para impulsioná-lo sejam consistentes nesse longo prazo, tendo em conta os impactos para além do momento presente, em termos de sustentabilidade, apropriação, etc.

Finalmente, em termos globais, a coê- rencia deve ser mantida também nas ações e nos discursos presentes nos diversos espaços e escalas de atuação, trabalhando-se com vistas a uma ação coletiva concertada. Nesse sentido, é compatível defender a segurança alimentar na FAO e, ao mesmo tempo, apoiar, nos foruns empresariais, a importância do extrativismo como via rápida para o desenvolvimento? É coerente a visão do desenvolvimento humano sustentável com o financiamento de empresas que deslocam os camponeses de suas terras ou que colocam em risco a própria existência desse território?

O caso da alimentação nos permite visibilizar essas tensões. Trata-se de um direito humano básico, elemento essencial do desenvolvimento humano e, portanto, também dos projetos de cooperação. O Brasil participa ativamente nos debates de desenvolvimento e no sistema de cooperação internacional em áreas muito diversas, mas com especial ênfase na agricultura e na alimentação, conseguindo se posicionar como uma referência internacional. Ao mesmo tempo, entrou com força no negócio mundial da agricultura, apostando por esse campo como motor do crecimento econômico e aproveitando, para isso, as oportunidades abertas nos mercados africanos. E no meio, tanto no âmbito interno como na dimensão transnacional, as redes camponesas denunciam os impactos sociais e ambientais do modelo de desenvolvimento agrícola dominante. A partir da citada definição da cooperação brasileira (IPEA, 2010), perguntamo-nos: que grupos vão ver melhoradas suas oportunidades e condições socioeconômicas: as populações africanas, com a garantia de seu direito à alimentação, ou as grandes empresas do agrobussiness, com a defesa do mercado de commodities?

Para dar respota a esse interrogante, é necessário definir, a partir de um enfoque global, os diversos discursos existentes em torno da alimentação (na defesa da soberania alimentar, da segurança alimentar ou ainda da financierização da alimentação) bem como as tensões e contradições geradas entre eles, em função das 
relações de poder entre os atores que os sustentam (principalmente o Estado, o setor privado e a sociedade). Posteriormente, será analisada a CSS brasileira com os países africanos no campo alimentar, para verificar como se resolvem ou não essas tensões nas práticas concretas e como elas se inserem no contexto mais amplo de relações entre o Brasil e os países africanos, tendo em conta outras políticas e outros atores envolvidos nessas relações.

\section{O DIREITO À ALIMENTAÇÃO: um campo em disputa}

\section{Discursos sobre alimentação: segurança, soberania ou oportunidade de negócio?}

A alimentação talvez seja a maior e mais urgente de todas as necessidades humanas, sendo reconhecida no artigo 25 da Carta das Nações Unidas (1948): “Toda a pessoa tem direito a um nível de vida suficiente para lhe assegurar e à sua família a saúde e o bem-estar, principalmente quanto à alimentação, ao vestuário, ao alojamento, à assistência medica [...]". Esse direito ganha força jurídica em 1966, com sua inclusão no artigo 11 do Pacto Internacional sobre Direitos Econômicos, Sociais e Culturais (PIDESC): ${ }^{2}$

Os Estados-parte no presente Pacto reconhecem o direito de toda pessoa a um nível de vida adequado para si próprio e para sua família, inclusive à alimentação, vestimenta e moradia adequadas, assim como uma melhoria contínua de suas condições de vida. [...]. 2) Os Estados [...] adotarão, individualmente e mediante cooperação internacional as medidas [...] para: a) Melhorar os métodos de produção, conservação e distribuição de gêneros alimentícios pela plena utilização dos conhecimentos técnicos e científicos, pela difusão de princípios de educação nutricional e pelo aperfeiçoamento ou reforma dos regimes agrários, de maneira que se assegurem a exploração e a utilização mais eficazes dos recursos

${ }^{2}$ A Comissão de Direitos Econômicos, Sociais e Culturais elaborou uma série de recomendações para dar conteúdo aos direitos do Pacto: a Observação no 12 de 1999 (E/c.12/1999/5) se refere ao direito a uma alimentação adequada. naturais. b) Assegurar uma repartição equitativa dos recursos alimentícios mundiais em relação às necessidades, levando-se em conta os problemas tanto dos países importadores quanto dos exportadores de gêneros alimentícios (PIDESC, 1966).

Esse reconhecimento - com a inclusão de referências à responsabilidade dos Estados, à cooperação internacional e à necessidade de um enfoque global para a distribuição dos recursos alimentícios - não impede que esse direito tenha sido objeto de diversas interpretações. A Organização das Nações Unidas para a Alimentação (FAO) o traduz como Segurança Alimentar e Nutricional (SAN), entendida como a garantia a todos de condições de acesso a alimentos básicos de qualidade, em quantidade suficiente, de modo permanente e sem comprometer o acesso a outras necessidades essenciais, com base em práticas alimentares saudáveis, contribuindo, assim, para uma existência digna, em um contexto de desenvolvimento integral da pessoa, com preservação das condições que garantam uma disponibilidade de alimentos em longo prazo (FAO, 1996).

A segurança alimentar implica, portanto, quatro dimensões essenciais: a disponibilidade física de alimentos, o acesso econômico e físico aos alimentos, o uso dos alimentos e a sustentabilidade, no tempo, das três dimensões anteriores (FAO, 2011). Esse conceito se vincula, muitas vezes, com o conceito de subnutrição, entendido como "a condição das pessoas cujo consumo de energía alimentar é constantemente inferior às necesidades mínimas de energia alimentar para poder levar uma vida saudável e realizar uma atividade física leve” (FAO, 2006, p. 2). Essa visão do direito à alimentação como segurança alimentar é compartilhada por grande parte das instituições internacionais e dos Estados. É o caso do Brasil, que incluiu, em 2010, o "direito à alimentação adequada" na Constituição Federal nos artigos $6^{\circ}$ e $277^{\circ}$, definindo-o na Lei Orgânica de Segurança Alimentar e Nutricional como: "o direito de cada pessoa de ter acesso físico e econômico, initerruptamente, à 
alimentação adequada ou aos meios para obter estes alimentos, sem comprometer os recursos para outros direitos fundamentais como saúde e educação".

Para além da incorporação na legislação interna, o Brasil tem desempenhado um relevante papel na defesa dessa visão no cenário internacional, com o responsável pelo desenho e pela implementação do programa Fome Zero, José Graziano da Silva, na direção da FAO desde 2012. Ou com o impulso de iniciativas como o Centro de Excelência da Luta contra a Fome ou o Fundo IBAS de Combate à Fome, entre outras muitas. Apoiou ainda a elaboração, em parceria com a FAO, de Diretrizes Voluntárias em apoio à realização progressiva do direito à alimentação adequada, que ressaltam a importância de uma ajuda alimentar internacional, o papel das instituições (e da participação cidadã, em particular dos grupos mais afetados pela insegurança alimentar) e a necessidade de que as políticas comerciais, nessa área, não coloquem em risco a segurança alimentar, dentre outras (FAO, 2004).

As políticas domésticas de combate à fome, que permitiram ao Brasil sair do mapa da fome da FAO (com menos de 5\% da população em situação de desnutrição), tornaram-se referências nesse campo. É o caso do programa Fome Zero, rapidamente percebido e construído por organismos multilaterais como modelo a ser promovido, e do Programa de Aquisição de Alimentos (PAA), que está sendo desenvolvido em cinco países africanos (Etiópia, Malaui, Moçambique, Níger e Senegal), em parceria com a FAO e o Programa Mundial de Alimentos (PMA). ${ }^{3}$ Os esforços têm dado resultados, mas não no ritmo esperado pelos objetivos de desenvolvimento do milênio: 750 milhões de pessõas continuam passando fome no mundo, e $30 \%$ delas estão na África (FAO, 2015a).

Nesse sentido, a visão de segurança alimentar ainda é considerada insuficiente por aqueles que veem, na alimentação, não só uma necessidade a ser coberta para a sobrevivência, mas também um indicador de dignidade e sociabilidade. "Alimento", nesse sentido, se constitui como prática cultural (Cascudo, 2011), "direito" e condição de "dignidade da pessoa humana" (Moraes, 2003). Para La Via Campesina (e com Mapa 1 - A desnutrição na África. Porcentagem de pessoas em situação de subnutrição, em 2015

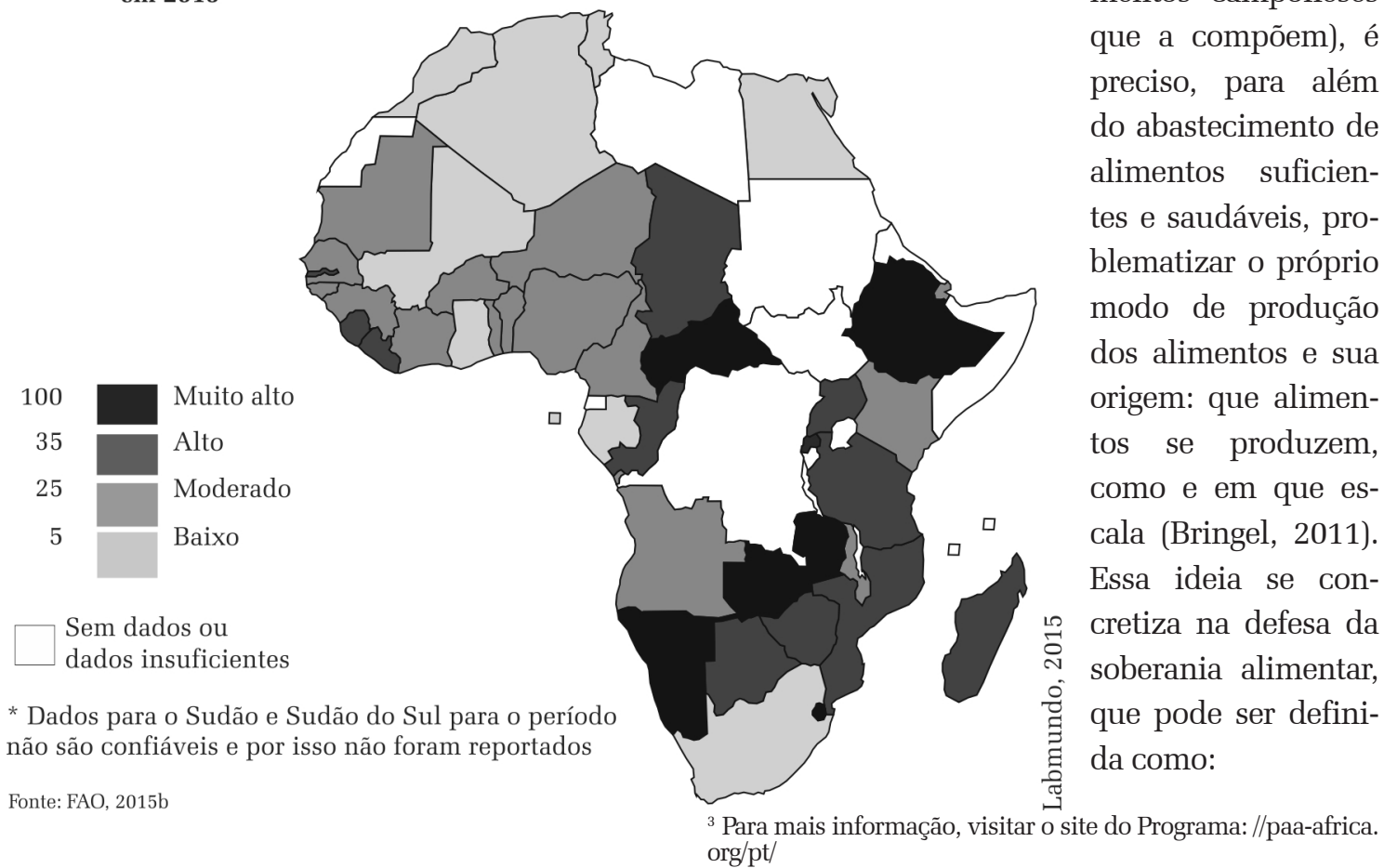
ela muitos dos movimentos camponeses que a compõem), é além do abastecimento de alimentos suficiendáveis, propróprio modo de produção tos se produzem, como e em que escala (Bringel, 2011). Essa ideia se concretiza na defesa da soberania alimentar, que pode ser definida como:

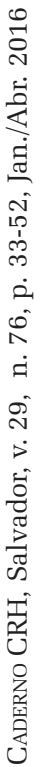


O direito dos povos a definir suas próprias políticas aimentares e agrícolas, proteger e regular a produção agropecuária nacional e o comércio para alcançar o desenvolvimento sustentável; determinar em que medida querem ser autossuficientes; restringir o dumping de produtos em seus mercados; e dar prioridade de uso e direitos sobre os recursos aquáticos para as comunidades que dependem da pesca. A soberania alimentar não nega o comércio, mas promove a formulação de políticas e práticas comerciais ao serviço do direito dos povos e das pessoas a uma produção segura, saudável e ecologicamente sustentável. ${ }^{4}$

Formam parte dessa visão, para além do aspecto nutricional, “[...] a apropriação e gestão dos recursos, a terra e o território, o comércio local e internacional, o desenvolvimento sustentável, a ação coletiva, a participação social, a agroecologia, o direito à alimentação e o modelo de produção." (Echart et al., 2013, p. 55). Esse enfoque exige adotar uma visão mais global da problemática e olhar não só para as pessoas que sofrem desnutrição, mas também para a geopolítica da fome (Castro, 1972), entendendo-a não como um fenômeno natural, e sim como o resultado do colonialismo e do imperialismo. Para Clapp (2012), as crises alimentares se vinculam com as dinâmicas de um capitalismo que converte os alimentos em commodities e em produtos financeiros e especulativos. A expansão do mercado internacional de alimentos, a força crescente de empresas * transnacionais voltadas para o agronegócio e a స financeirização da agricultura são dinâmicas estreitamente vinculadas à atual geopolítica da

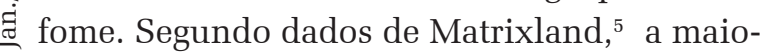
iิ ria das terras que está sendo adquirida pelas m grandes empresas não é utilizada para a produ@̧ ção de alimentos: apenas $10 \%$ são destinadas a à produção de sementes para alimentação. No is lado oposto, $70 \%$ das pessoas que sofrem com $\therefore$ a fome no mundo são pequenos agricultores.

${ }^{4}$ Declaração do Fórum para a Soberania Alimentar de Nyéléni, em 2007 (Bamako, Mali), disponível em: http:// www.nyeleni.org

${ }^{5}$ Dados disponíveis no site de Matrixland: http://www. landmatrix.org/en/get-the-idea/agricultural-drivers/

\section{O Brasil: entre a agricultura familiar e o agronegócio}

O Brasil, pela sua experiência interna e sua projeção internacional, tem sido percebido, no cenário internacional, como um parceiro desejável no campo da segurança alimentar e nutricional. No entanto, junto à sua defesa da alimentação, o país também apoia o agronegócio como um setor importante de um desenvolvimento fomentado pelo crescimento econômico. Na sua posição semiperiférica, vive hoje um processo de reprimarização da economia, impulsionada, em grande medida, pela exportação de commodities e pela mercantilização da agricultura. Acompanhando o discurso da "vocação agrícola” dos países do Sul, ${ }^{6}$ verifica-se uma divisão internacional da produção que especializa o Sul na produção de commodities agrícolas para exportação. Nesse sentido, durante a Reunião de Alto Nível da FAO sobre Segurança Alimentar e Mudanças Climáticas, em 2008, Lula, então presidente do Brasil, defendia:

\footnotetext{
Está na hora de os analistas políticos e econômicos avaliarem corretamente a capacidade de contribuição dos países em desenvolvimento na questão de alimentos, energia e mudanças climáticas. Cerca de 100 países têm vocação natural para produzir biocombustíveis de forma sustentável. Esses países terão de fazer seus estudos e decidir se podem ou não produzir biocombustíveis, e em que extensão. Precisarão definir as plantas mais adequadas e escolher projetos em função de critérios econômicos, sociais e ambientais (Lula, 2008 apud Carvalho, 2013, p. 80).
}

No modelo de desenvolvimento agrário brasileiro, essa posição vai gerar tensões internas, em virtude do complexo entrelaçamento entre os interesses públicos e privados no âmbito das políticas agrárias nacionais de desenvolvimento, pautadas, de um lado, no modelo

\footnotetext{
${ }^{6}$ Iniciado ainda na década de 1960, a partir do "Programa Alimentar Mundial", que, anos mais tarde, culminaria no amplo projeto de remodelacão do campo por meio de técnicas superdesenvolvidas de cultivo de sementes, conhecido como Revolução Verde, tal discurso atualmente segue presente, mas sob nova roupagem. Excluem-se, com essa especialização, as demais possibilidades de desenvolvimento industrial e científico para estimular e financiar tal produção (Carvalho, 2013).
} 
agroexportador latifundiário, representado institucionalmente pelo Ministério da Agricultura, Pecuária e Abastecimento (MAPA), e, do outro, no modelo de agricultura familiar do Ministério do Desenvolvimento Agrário (MDA). Com a criação do MDA, em 1998, o Brasil institucionalizou uma abordagem dualista do seu setor agrícola, separando o apoio à agricultura familiar do apoio à agricultura patronal (Sabourin, 2007). A divisão ministerial, bem como a criação do Programa Nacional de Agricultura Familiar (PRONAF), em contrapartida ao Sistema Nacional de Crédito Rural (SNCR) - na prática a serviço apenas dos grandes produtores rurais - serviram para responder às demandas por reforma agrária (Acserald, 2012), ainda que com um quadro flagrante de distribuição desigual e de hegemonia do agronegócio. Esse último era visto como "uma agricultura capitalista competitiva e provedora de divisas", em contraposição à "pequena produção de subsistência, camponesa e atrasada” (Sabourin, 2007, p. 718).

O Brasil está na liderança mundial dessas commodities, como o maior produtor de cana de açúcar e o segundo maior produtor de soja do mundo, detendo um domínio biotecnológico eficiente graças às pesquisas de melhoramento genético desenvolvidas pela Empresa Brasileira de Pesquisa Agropecuaria (Embrapa). Isso faria do Brasil o produtor de biocombustíveis mais eficiente do mundo (Banco Mundial e IPEA, 2011). Países de condições climáticas e geológicas semelhantes às do Brasil têm aderido a acordos de cooperação para a produção de biocombustíveis visando à transferência dessa tecnologia de ponta e ao domínio das técnicas mais eficientes. Do lado brasileiro, a cooperação também é bastante atrativa para a internacionalização de suas empresas que, por exemplo, terão acesso facilitado para exportar commodities produzidas na África para a União Europeia sem as mesmas tarifas impostas ao Brasil. A União Europeia, por seu lado, tem grande interesse em negociar biocombustíveis para atingir metas internacionais de redução de emissão de carbono a custos bem menores do que teria para modificar suas fontes energéticas. Por outro lado, a internacionalização dessa produção pode ajudar a aumentar a produtividade, externalizando os custos socioambientais. Lembremos a alta conflitividade no campo brasileiro (Comissão Pastoral da Terra, 2014), com fortes críticas aos riscos da monocultura e do uso de plantas transgênicas, bem como ao desmatamento, aos despejos derivados dessa produção e à concorrência com terras aráveis necessárias à produção de alimentos em seu território.

Essas incoerências, verificadas no âmbito interno, são suscetíveis, portanto, de exportação, juntamente com as políticas que as promovem. Agronegócio e agricultura familiar, no contexto brasileiro, são tratados como faces incompatíveis e, ao mesmo tempo, coexistentes e assimétricas de uma mesma política de desenvolvimento agrário, produzindo incoerências não só entre os ditados de uma lei que protege o direito à alimentação e as práticas do agronegocio que podem colocar esse direito em risco, mas também entre os diversos discursos e práticas que o governo mantém nos diferentes espaços, internos e internacionais.

Com esse cenário de fundo, convém analisar, agora, a atuação brasileira no continente africano e o impacto que ela pode ter para os diversos atores envolvidos. Tal atuação contribui para a melhoria da segurança alimentar das populações africanas, ou está favorecendo a internacionalização das empresas brasileiras? Os crescentes conflitos sociais em torno da terra parecem indicar que ambas as estrategias não são compativeis, o que deve ser levado em conta ao se avaliar a coerência de políticas, garantindo que o desenvolvimento dos países parceiros, apoiado pelos projetos de CSS, não seja perjudicado por outras políticas ou práticas de anticooperação.

\section{RELAÇÕES ENTRE BRASIL E ÁFRICA NO CAMPO DA ALIMENTAÇÃO}

As relações entre o Brasil e os países africanos cresceram na última década, princi- 
palmente nos governos Lula, diversificandose as parcerias: visitas diplomáticas, abertura de embaixadas, acordos de defesa, comércio, investimentos, posições comuns em espaços multilaterais, maior presença de empresas brasileiras, etc. (Banco Mundial e IPEA, 2011). Essa retomada ocorre em um momento em que os países em desenvolvimento se veem como capazes de cooperar entre si, "a fim de garantir reformas políticas da governança global (FMI, Banco Mundial, ONU) e resolver seus próprios problemas econômicos e sociais com base em identidades compartilhadas (ex-colônias, status econômico, experiência histórica, etc.), esforços comuns, interdependência e reciprocidade" (Milani e Carvalho, 2013 p. 15). A CSS com o continente africano se enquadra dentro dessa intensificação de relações, e, portanto, tem de ser analisada também nesse contexto, entendendose as diversas políticas e os atores envolvidos. Só dessa forma conseguiremos visibilizar atores e práticas que, apesar de excluídos da definição estrita da cooperação brasileira (IPEA, 2010), interagem, tensionam ou se beneficiam dela. Um dos exemplos mais claros é a "promiscuidade" entre cooperação, investimento e financiamento (Beghin, 2014, Garcia e Kato, 2012).

No campo da agricultura, climas semelhantes, raízes históricas e culturais e status político são alguns dos elementos advogados para * explicar a atuação brasileira na África. Devido त̀ às semelhanças geofísicas de solo e de clima, a tecnologia brasileira parece ser de fácil adaptabi을 lidade a muitos países africanos (Banco Mundial ิิ เิ e IPEA, 2011). Tais semelhanças tornam o Brasil \% um parceiro "natural" com o continente e trazem, í a priori, uma boa receptividade à CSS brasileira. ¿ Mas qual é o objetivo central dessa cooperação? oิ Que benefícios ela traz para os parceiros envolvidos? Qual é a posição do continente africano?

\section{Africa: terra de oportunidades para quem?}

Grande número de artigos e relatórios ressaltam, nos últimos tempos, as imensas oportunidades que se abrem para o continente africano no novo milênio. ${ }^{7}$ As taxas de crescimento econômico (cerca de 5\% em um momento de contração geral da economia), a alta disponiblidade de terras aráveis, o campo ainda por explorar, a crescente presença de investimentos estrangeiros diretos, etc. fazem do continente africano um lugar muito atrativo. E a agricultura tem aí uma grande importância. No que alguns denominam a "nova batalha por África" (Carmody, 2011), as potências emergentes - dentre elas, o Brasil - também desempenham um papel relevante,$^{8}$ fazendo dos países africanos parceiros essenciais de suas estratégias de cooperação Sul-Sul (CSS). No entanto, convém perguntar sobre o tipo de oportunidades que, de fato, estão sendo geradas e a quem elas estão beneficiando. $\mathrm{O}$ tom dos artigos citados nos dá uma primeira pista: o setor privado - e, dentro dele, as empresas do agronegocio $^{9}$ - parece ser o impulsionador da nova fase de esperança em um continente que ainda enfrenta grandes desafios em termos de desenvolvimento humano, em dimensões tão básicas como a alimentação.

Esse território rural, rico em recursos naturais (petróleo, gás, urânio, diamantes, coltan, etc.), é apresentado como a última grande fronteira agrícola, com $60 \%$ das terras potencialmente aráveis do planeta (muitas delas em mãos estrangeiras). O Programa de Nações

7 À guisa de ilustração: Forbes (28/12/2011): “Top 5 Investment Opportunities In Africa For 2012" (em http:// www.forbes.com); CanaMix: "Crescem oportunidades de negócios para brasileiros em países da África" (http:// www.canamix.com.br); BNDES (03/05/2012): "Seminário no BNDES destaca oportunidades de investimento e cooperação no continente africano" (http://www.bndes.gov. br); Banco Mundial (2013): "Growing Africa: Unloking the Potencial of Agrobussiness" (http://www-wds.worldbank. org); ONU (15/10/2015): "Relatório revela oportunidades para desenvolver infraestruturas em África", (http://www. unmultimedia.org), dentre tantas outras.

${ }^{8}$ Há uma presença cada vez maior de empresas dos BRICS no continente, nas áreas de mineracão, produção de hidrocarbonetos, construção, etc. Ver: BRICS on the Heels of Africa" (http://bricsmagazine.com/en/articles/brics-onthe-heels-of-africa). Entre as empresas brasileiras, destacam-se: Petrobras, Odebrecht, Vale, Andrade Gutierrez, Camargo Corrêia, etc.

${ }^{9}$ Dentre as 500 principais empresas no continente, o agronegócio ocupa um lugar importante. Esse top 500 está disponível em: http://www.theafricareport.com/top-500-companies-in-africa-2013.htm. 
Unidas para o Desenvolvimento adverte sobre a possível batalha pela terra que isso pode gerar no continente (PNUD, 2012, p. 9). A agricultura tem um peso importante nas economias africanas: mais de um terço do produto interno bruto, para países como Benim, Burundi, Malaui, Niger, Ruanda ou Tanzânia, e supera 50\% do PIB para Chade ou Serra Leoa. Uma parte muito importante da população, cerca de $60 \%$, vive nessas áreas rurais (em torno a $80 \%$ nos casos de Burundi, Chade, Eritreia, Etiópia, Malaui, Niger, Sudão do Sul ou Uganda). Mas, ao mesmo tempo, essas famílias sofrem de subnutrição: o impacto da pobreza é muito maior nas áreas rurais (mais de 70\% da população rural se situa abaixo da linha da pobreza em países como Congo, Gâmbia Guiné-Bissau ou Togo) (Banco Mundial, 2015). Além disso, as mulheres constituem $60 \%$ da população rural, mas elas ainda não têm reconhecido, em muitos casos, o direito à propriedade da terra, o que incrementa sua vulnerabilidade (FAO, 2012).

Aliás, enquanto o agronegócio vê com grande interesse a região, para o PNUD, a segurança alimentar se define como a preocupação central do Relatório de Desenvolvimento Humano (PNUD, 2012). O alto crescimento econômico não está tendo um impacto direto na melhoria da situação de pobreza, desnutrição ou desigualdade na região. Hoje, uma em cada quatro pessoas continua sofrendo de desnutrição na África, ${ }^{10}$ o que faz do continente um dos grandes receptores de ajuda alimentar.

Claro que grande parte do território arável disponível encontra-se em mãos estrangeiras (mais de 15 milhões de hectareas), majoritariamente no Sudão, no Sudão do Sul e em Moçambique, que são, ao mesmo tempo, países com desnutrição alarmante. Como adverte Matrixland, ${ }^{11}$ uma explicação pode ser o fato de que poucas dessas terras são efetivamente utilizadas para a produção de alimentos (em

${ }^{10}$ Para mais informação: https://es.wfp.org/hambre/datosdel-hambre

${ }^{11}$ Dados disponíveis em: http://www.landmatrix.org/en/ get-the-idea/agricultural-drivers/ torno de 13\%). Nesse contexto, o reclame por mais eficiência no campo termina repercutindo em maiores benefícios para essas grandes empresas, não para a melhoria das condições nutricionais da população, e muito menos para a soberania alimentar.

Os dados macroeconômicos, a modernização, o incremento da eficiência ou a inserção na economia global, defendidas pelas associações público-privadas, ocultam, assim, os efeitos desse modelo de desenvolvimento nas pessoas e na natureza, na justiça social e ambiental. Os diversos conflitos e reivindicações de movimentos e organizações sociais, principalmente camponeses, mostram, no entanto, que se trata de um campo em disputa.

\section{A COOPERAÇÃO SUL-SUL BRASI- LEIRA PARA O DIREITO À ALIMEN- TAÇÃO}

Com esse cenário de fundo, a cooperação brasileira no campo da alimentação se apresenta como uma oportunidade de melhorar a situação nutricional no continente. Muitas são as possibilidades abertas por uma CSS que porporcionou maior oxigenação no leque de escolhas de parcerias por parte dos países do Sul na senda do desenvolvimento. A maior horizontalidade e flexibilidade, as possibilidades de adaptação e de troca de experiências semelhantes, a ausência de condicionalidades e as identidades compartilhadas eram alguns dos benefícios apresentados por essas novas formas de cooperação (Corrêa, 2011). O que, no nível sistêmico, pode parecer uma grande mudança no sistema internacional de cooperação para o desenvolvimento, desafiando a verticalidade das relações Norte-Sul, deve, no entanto, ser contrastado com os reais alcances da cooperação, os atores envolvidos, os efeitos e contradições que pode estar gerando.

África possui grande relevância na CSS brasileira, respondendo por $39,5 \%$ do total do orçamento governamental em cooperação 
técnica (Milani et al, 2014). Apesar da atuação em diversas áreas, como saúde e educação, é em desenvolvimento agrícola e alimentação que o Brasil atua de forma mais intensa. Segundo dados do CAISAN (2013), cerca de $62 \%$ da cooperação brasileira no setor e $46 \%$ dos montantes financeiros são destinadas ao continente africano, com atuação em 32 países.

As principais modalidades de CSS brasileira em segurança alimentar e nutricional são (Beghin, 2014):

1. Fortalecimento da agricultura de pequeno porte (20\% do total de projetos): trata-se de projetos de capacitação em agroecologia (na República Democrática do Congo), aumento da produção familiar de mandioca (no Quênia), ou apoio ao desenvolvimento do setor algodoeiro (no marco do Cotton 4), dentre outros.

2. Produção e processamento de alimentos (18\%), como apoio ao desenvolvimento da horticultura em Cabo Verde, ou o desenvolvimento do caju em Gana.

3. Acesso a alimentos em situação de emergencia (16\%): são projetos de nutrição emergencial para crianças menores de cinco anos (caso da Angola), ou de assistência alimentar para refugiados (na Namíbia).

4. Alimentação escolar (14\%), com projetos de fortalecimento de programas de alimentação escolar (em Libéria, Níger, Maláui, Senegal, Ruanda, Gana, Costa do Marfim, etc.).

5. Outros, como o acesso a alimentos a partir de compras locais da agricultura familiar (caso do PAA África no Senegal, Maláui, Moçambique, Níger e Etiópia), pesca (como o projeto de organização e desenvolvimento da cadeia produtiva da pesca e aquicultura na Mauritânia), regulação de alimentos (caso da consolidação da Arfa como agente regulador dos setores farmacêutico e alimentar de Cabo Verde), etc.

Como podemos ver, a maioria dos projetos dessa cooperação está, de fato, voltada para pautas de segurança alimentar e nutricial, o que poderia ser sintomático da importância dessa questão na CSS brasileira. Contudo, ao cruzar o número de projetos com os valores destinados à agricultura familiar, o tamanho dessa cooperação se reverte. A maioria dos projetos de segurança alimentar são projetos menores, pontuais, de atuação mais localizada. O relatório do CAISAN (2013) indica que, em termos de valores, $25 \%$ dos fundos estariam direcionados para projetos em agricultura e apenas 9\% para segurança alimentar.

Em relação aos atores, a primeira observação que pode ser feita é a presença de atores governamentais muito diversos: Itamaraty, Agência Brasileira de Cooperação, Empresa Brasileira de Pesquisa Agropecuaria (Embrapa), Ministério de Desenvolvimeto Social, Ministério de Desenvolvimento Agrario, Serviço Nacional de Aprendizagem Rural (SENAR), agências multilaterais (como a FAO ou o PMA), mas também o Banco Nacional de Desenvolvimento Econômico e Social (BNDES), a Agência de Promoção de Exportações e Investimentos do Ministério de Desenvolvimento, Indústria e Comercio Exterior (APEX/MDIC), entre outros.

O Ministério do Desenvolvimento Agrário exerce função importante na defesa de políticas que promovem o desenvolvimento da agricultura familiar. Seu papel nos projetos de cooperação consiste em: garantir infraestrutura rural, comercialização de produtos agrícolas e acesso a mercados; apoiar a agricultura familiar; reduzir a fome e aumentar a produção de alimentos; pesquisar, desenvolver e disseminar tecnologia agrária; desenvolver a capacidade institucional no âmbito da segurança alimentar e da nutrição; desenvolver modelos comparativos para a África com o uso de tecnologias adaptadas; e garantir o desenvolvimento de estratégias para a consecução da segurança alimentar, combate à fome e desenvolvimento rural (Banco Mundial e IPEA, 2011). O SENAR também contribui com a formação agrícola e profissional dentro dos projetos de cooperação, em áreas como agricultura e agroindústria, aquicultura, silvicultura, agricultura pastoral, prestação de serviços, extrativismo e produção 
agropecuária, além de organização comunitária, saúde, esportes e cultura. Atua geralmente trazendo profissionais africanos para regiões brasileiras com condições ambientais semelhantes às de suas regiões.

Destaque especial merece a Empresa Brasileira de Agropecuária (Embrapa), uma empresa estatal vinculada ao Ministério da Agricultura, Pecuária e Abastecimento (MAPA) e voltada para o desenvolvimento tecnológico do agronegócio brasileiro, que se tornou um ator central na cooperação agrária brasileira, sobretudo nas áreas de biotecnologia e bioenergia. Está presente em muitos países em desenvolvimento, seja por meio de parcerias em projetos específicos, seja de modo mais constante nos países em que possui escritórios. Hoje atua em projetos de cooperação técnica com 56 países e instituições estrangeiras. Em coordenação com a ABC, a Embrapa abriu escritório em Gana e criou unidades de coordenação em todos os países com projetos em andamento. Ademais, há um forte envolvimento de institutos de pesquisas e universidades na tentativa de transpor os projetos de maior êxito no Brasil para regiões africanas de clima semelhante.
A cooperação técnica da Embrapa se divide em: 1) projetos estruturantes, com um alto volume de recursos financeiros (superior a um milhão de dólares), com mais de dois anos de duração, que contam com a presença permanente de um profissional da Embrapa no país para coordenar as atividades, que podem ser em parceria com a ABC e agências internacionais; 2) projetos pontuais, de menor porte e curta duração; 3) capacitação em cursos de agricultura tropical; 4) plataformas de inovação agropecuária (Maluf et al., 2014: $34)$.

Os projetos estruturantes geram uma presença mais intensa e maiores impactos. Esses projetos têm efeitos positivos, por agregar atividades (aumentando, assim, o impacto e a sustentabilidade do projeto), facilitar as parcerias nacionais e internacionais e oferecer uma estrutura mais robusta de acompanhamento dos processos de implementação (Abreu, 2013). No entanto, também acumulam uma maior quantidade de contradições e produzem maiores questionamentos sobre a coerência das políticas da CSS brasileira.

A cooperação agrícola brasileira com os países da África sustenta, em seu discurso, a importância de promover projetos voltados para segurança alimentar da região. Contudo, boa parte deles está direcionada à produção de commodities para a exportação. A própria Embrapa se vê envolvida em projetos bem distintos, e, em certas ocasiões, com objetivos incompatíveis, como, por exemplo, no caso do Moçambique: de inovação agraria (o Plataforma), de desenvolvimento da agricultura (o ProSavana) e de segurança ali- 
mentar e nutricional (o ProAlimentos). ${ }^{12}$

Apesar da boa acolhida inicial da CSS brasileira, essas diversas atuações, ambíguas e até contraditórias, estão levando a uma crescente perda de credibilidade (Beghin, 2014). A combinação de visões, dentro dos projetos estruturantes, exige refletir sobre a possibilidade de coexistência de duas formas de pensar a cooperação para o desenvolvimento, replicando as próprias ambiguidades internas do Brasil em relação ao modelo de desenvolvimento agrário, que se debate entre a defesa da segurança alimentar e a hegemonia de um modelo agroexportador. Dentre as críticas à atuação do Brasil em segurança alimentar encontram-se: "falta de informações e ausência de transparência, descoordenação das ações, alcance limitado dos projetos, exportação das contradições nacionais (como, por exemplo, a promoção da agricultura familiar e o estímulo à expansão do agronegócio), associação com agendas de interesses econômicos e comerciais em detrimento do efetivo desenvolvimento sustentável, baixa capacidade de adaptar-se às reais condições locais.” (Beghin, 2014).

${ }^{12}$ Cooperação Técnica de Apoio à Plataforma de Inovação Agrária de Moçambique é um projeto nas áreas de pesquisa, desenvolvimento e transferência de tecnologia para a autossuficiência na produção de alimentos. Inclui fortalecimento de áreas estratégicas, como estudo dos solos e modernização do setor de sementes, além da comunicação para a transferência de tecnologias e o planejamento es-

๑ tratégico. O ProSavana (Projeto de Melhoria da Capacida-

$\rightarrow$ de de Pesquisa e de Transferência de Tecnologia para o

$\checkmark$ Desenvolvimento da Agricultura no Corredor de Nacala),

فे de iniciativa trilateral, permitiria a aquisição, por parte

\& do Brasil e do Japão, de mais de 14.5 milhões de hecta-

res de terras moçambicanas para serem concessionadas a

ฮ્ grandes empresas agroexportadoras brasileiras e japonesas

* (monoculturas de soja, milho, girassol, algodão) ao longo

LP do chamado Corredor de Desenvolvimento de Nacala,

๗ com forte incidência em 19 distritos. É um dos projetos

$\dot{2}$ de cooperação mais criticados, gerando fortes denúncias

- dos movimentos sociais locais. Já o projeto de segurança

$\diamond$ alimentar é uma iniciativa trilateral entre Brasil, Estados

¿ Unidos e Moçambique, para fortalecer a produção de hor-

- taliças por agricultores familiares e (ou) de subsistência e

is direcionar os produtos para o mercado da capital Maputo,

$>$ tornando o país autossuficiente na produção de hortaliças.

ثิ O projeto faz parte da Iniciativa Global de Combate à Fome

E Segurança Alimentar. Para além da atuação no Moçam-

\pm bique, a Embrapa desenvolve outros projetos estruturan-

क tes, como o Cotton-4, com Benim, Burquina Faso, Chade

. e Mali, visando a melhorar a produtividade cotonícola.

Foi o primeiro projeto estruturante do governo brasileiro

U no setor agrário, com 33 missões técnicas enviadas pela

Embrapa às instituições locais, e terminou se ampliando

para Togo e Zambezia. Também o projeto Rizicultura, no

Senegal, busca oferecer técnicas mais eficientes e diversi-

f ficadas de cultivo.
Parte dessas críticas implica olhar, como dizíamos no inicio, para além da própria CSS, ou seja, para o conjunto de práticas com incidência no desenvolvimento dos parceiros africanos. O principal problema sobre a atuação brasileira no setor é justamente a dificuldade de identificar onde termina a cooperação e onde começa o investimento e a internacionalização das empresas. A própria definição da CSS - como constituída de 100\% atividades implementadas a fundo perdido - leva a excluir os financiamentos, os investimentos e a participação de empresas brasileiras com interesses econômicos para quantificar o alcance da cooperação, embora, na prática, esses elementos sejam indissociáveis (Garcia e Kato, 2012). Tendo em vista a confluência de distintos interesses e atores que incidem sobre a cooperação brasileira, devem se mostrar aqueles que transbordam o nacional e passam a incidir suas demandas internacionalmente, como, no caso, as interações entre o público e o privado, na hora de definir as prioridades e objetivos dessa cooperação.

\section{Abertura de um campo de oportunidades para as empresas}

Muitos têm avisado sobre a estreita relação, ou a "promiscuidade" entre cooperação, financiamento e investimento (Garcia e Kato, 2012; Beghin, 2014). Uma amostra dessa estreita relação se vê na importância da diplomacia oficial como impulsora das missões empresariais. ${ }^{13}$ Também o apoio do Banco Nacional de Desenvolvimento Econômico e Social (BNDES) é muito relevante nesse sentido, promovendo a exportação (através do PROEX), o investimento direto externo (com o Programa BNDES-Exim) e a internacionalização de em-

${ }^{13}$ Por exemplo, a visita do Chanceler Mauro Vieira a vários países africanos, entre eles Camarões e Senegal, em agosto e setembro de 2015, na qual se incluiram encontros empresariais sobre oportunidades de negócios, organizados pelo Departamento de Promoção Comercial e Investimento e a Agência Brasileira de Promoção de Exportações e Inverstimentos (Apex-Brasil). Mais informação em: http:// eventos.dpr.gov.br/Sites/Africa/ 
presas brasileiras.

A África se apresenta, no cenário internacional, como um campo de oportunidades impulsionado por dois eixos de dinamismo: a produção de commodities para exportação e o desenvolvimento da infraestrutura, com grandes projetos concentrados em energia e logística (Vieitas e Aboim, 2013). Esse dinamismo se reflete nas relações com o Brasil: o comércio passou de US\$ 4 bilhões, em 2000, para US\$ 20 bilhões em 2010, ao tempo que se ampliaram os investimentos externos diretos (IED), com peso da construção, da mineração e, em menor medida, da agricultura (Vieitas e Aboim, 2013; Veiga e Rios, 2015). O bom momento do desenvolvimento econômico nacional, nos anos 2000, também repercutiu na busca por inserção internacional de parcela significativa das empresas do agronegócio brasileiro (Belik, 2010).

Mapa 3 - Empresas Brasileiras na África - número de empresas por país

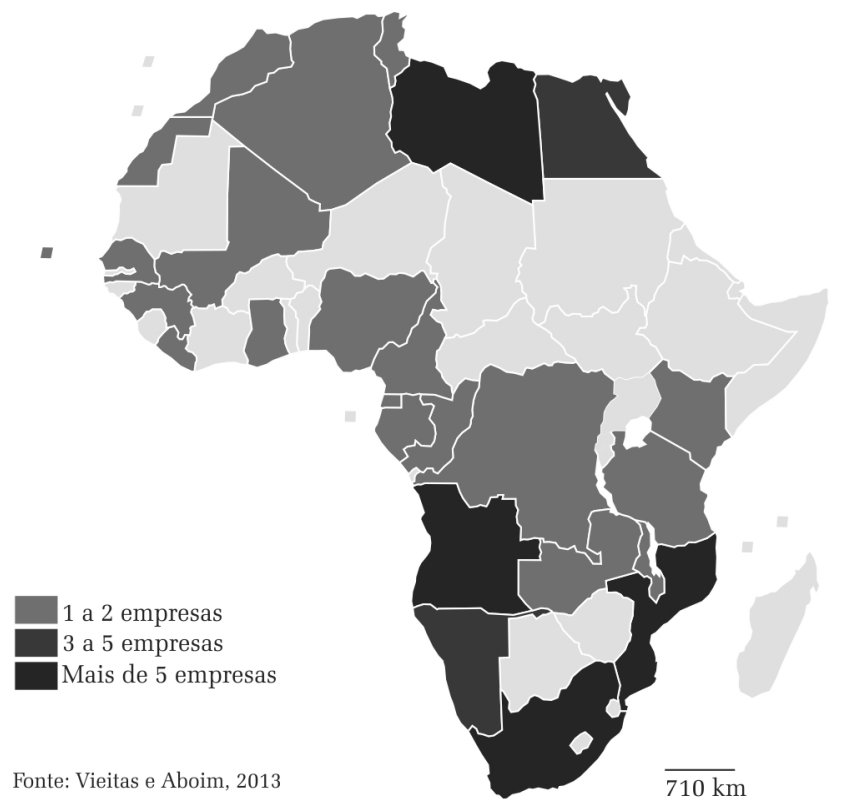

As empresas brasileiras, "atraídas pela grande disponibilidade de recursos naturais e pela demanda de obras de infraestrutura" (Vieitas e Aboim, 2013, p. 20), interessaram-se pelo continente, e hoje estão presentes em uma trintena de países. O Ranking das Transnacionais Brasileiras de 2013 sublinha os impactos da política externa brasileira nesse processo de crescente internacionalização de empresas, como JBS, Gerdau, Stafinini ou Vale (Fundação Dom Cabral, 2013). Cabe destacar que, dentre as dez empresas mais transnacionalizadas, encontram-se três dedicadas ao setor alimentar (JBS-Friboi, Marfrig Alimentos e Minerva Foods). Para além desse setor, as empresas brasileiras se concentram na construção civil (com 9 empresas), indústria (4), óleo e gás (3) e mineração (2) (Vieitas e Aboim, 2013).

Muitos desses investimentos são incentivados e contam com apoios públicos, sendo o BNDES um ator-chave no processo de internacionalização de empresas brasileiras, atuando em relação estreita com alguns dos projetos de cooperação analisados. ${ }^{14}$

A abertura do escritório do BNDES na África do Sul e a negociação de acordos de cooperação e facilitação de investimentos (ACFI) com África do Sul, Angola, Moçambique e Malaui respondem ao objetivo de "facilitar e promover investimentos diretos de empresas brasileiras no continente africano" (Veiga e Rios, 2015, p. 26). Além das empresas do agronegócio, beneficiamse construtoras e mineradoras que atuam junto a projetos que visam a desenvolver a infraestrutura regional, muitas vezes voltadas para o escoamento de recursos naturais para exportação. Se esse apoio contribui para o fortalecimento do setor pri-

14 Para Beghin, “...um exemplo que ilustra esses arranjos é a região norte de Moçambique: lá estão a Vale, com a exploração de minério [...]; a Odebrecht, com a construção de porto e aeroporto; e a cooperação brasileira com o projeto Prosavana. Como se isso não bastasse, existe um movimento, que conta com o apoio do governo brasileiro, de criação do Fundo de Investimentos em Agricultura para o corredor de Nacala, conhecido como Fundo Nacala. Prevê-se um montante inicial de US\$ 2 bilhões na agricultura, recursos que devem ser captados em empresas do Brasil e do Japão, no Banco mundial e em instituicões financeiras dos três países, para financiar o desenvolvimento do agronegócio na referida região.” (Beghin, 2014, p. 50). 
vado brasileiro, também tem sido objeto de denúncias por violação de direitos humanos e degradação ambiental. Os casos do ProSavana em Moçambique, ${ }^{15}$ os protestos contra a Vale (que já criaram uma rede internacional de atingidos pela Vale ${ }^{16}$ ), ou contra a Odebrecht, ${ }^{17}$ entre outros, mostram os impactos negativos que esses operadores privados estão provocando em termos de desenvolvimento humano.

O BNDES ainda assinou acordos com o Banco Africano de Desenvolvimento e com New Partnership for Africa's Development (NEPAD) para explorar possíveis colaborações, no setor da bioenergia e do biodiesel, com Senegal, Zambia e Moçambique como possíveis parceiros (Milhorande, 2015). Trata-se de um setor que já gerou fortes denúncias pelos impactos sociais e ambientais que esses monocultivos produzem em grande escala, além da grande demanda de terras que exigem.

Finalmente, outro exemplo dessas interações público-privadas é o próprio programa Mais Alimentos (MAI), lançado em 2010 pelo então Presidente Lula no marco do Diálogo Brasil - África em segurança alimentar, combate à fome e desenvolvimento rural. Esse projeto, coordenado pelo Ministério de Desenvolvimento Agrário, recebe "boa parte dos créditos concessionais à exportação [...] e tem como um dos seus principais objetivos fomentar as exporta-

ㄱ ${ }^{15}$ As denúncias contra esse projeto levaram a um campaق nha que mobilizou diversos atores sociais moçambicanos e

brasileiros. Ver: http://www.unac.org.mz/index.php/compo-

हु nent/content/?view=featured\&start=75; http://viacampesi-

F na.org/en/index.php/actions-and-events-mainmenu-26/stop-

กิ transnational-corporations-mainmenu-76/1650-no-to-pro-

m s savana-campaign-mozambicans-seek-regional-solidarity.

$2{ }^{16} \mathrm{O}$ Documento Político do V Encontro Internacional das

6 Atingidas e Atingidos pela Vale, em agosto de 2015, denun-

- ciava: "Os Estados Nacionais dos países onde a Vale opera

A são cúmplices dessas violações cometidas pela empresa,

on em especial o Estado Brasileiro por deter açôes da empresa

- e financiar com recursos públicos subsidiados do BNDES

$>$ tais operações. A assinatura de convênios e acordos entre

ثิ Estados e a Vale às custas dos direitos dos trabalhadores e

das comunidades e o fomento aos grandes projetos de de-

\pm senvolvimento econômico contribuem para a perpetuação

ஸू das desigualdades sociais, como, por exemplo, no acesso à

- terra". Ver: https://atingidospelavale.wordpress.com

${ }^{17} \mathrm{Um}$ dos últimos escándalos internacionais que envol-

vem essa empresa foi a condenação por trabalho escravo

e tráfico de pessoas em Angola. Ver: http://www.bbc.com/

portuguese/noticias/2015/09/150831_odebrecht_angola_ condenacao pai jf ções de máquinas, tratores e equipamentos aos países em desenvolvimento via crédito concessional” (Viega e Rios, 2015, p. 31). Assim,

[...] executado com recursos orçamentários do Proex-Financiamento, o MAI tem sua origem na esfera da cooperação técnica bilateral, desdobra-se em um instrumento (memorando de entendimento) acerca das condições de financiamento da exportação de produtos brasileiros e, na sequência, em um mecanismo de apoio governamental à exportação de máquinas agrícolas brasileiras (Viega e Rios, 2015).

À medida que os modelos de gestão e os projetos se internacionalizam, o interesse empresarial passa a ser replicado também nessa esfera (Belik, 2010). A temática da segurança alimentar é apropriada por empresas como indicador de "responsabilidade social e ambiental", o que dificulta o estabelecimento de uma linha divisória entre ética e interesses por crescimento econômico na construção de parcerias público-privadas. Por outro lado, a não participação formal das empresas nos projetos de cooperação torna difícil o controle de suas práticas, sobretudo no cumprimento de direitos humanos em relação a trabalho escravo, expulsão de familiares de suas terras, sobreexploração dos recursos, etc., em benefício de uma visão mercantil da agricultura. O que não aconteceria no caso de se garantir uma soberania alimentar como base do direito à alimentação.

Assim, a ambivalência entre agronegócio e agricultura incide, inclusive, nas políticas brasileiras de cooperação em segurança alimentar, repercutindo em sua política externa e sua credibilidade. Tal credibilidade só pode ser mantida enquanto se invisibilizem os impactos sociais e ambientais de tal modelo. Nesse sentido, enquanto, no discurso da cooperação em segurança alimentar e nutricional prevalece o modelo de agricultura familiar, na medida em que preza pela autossuficiência alimentar da população, nas atividades práticas a CSS tem agido em consonância com um modelo de desenvolvimento agrário voltado para a exportação de commodities agrícolas que atendem a demandas do mercado internacional, mas não 
sanam déficits alimentares locais.

Desse modo, a CSS se mostra não tanto como uma prática governamental isenta de condicionalidades, e sim como responsável por uma parceria entre o público e o privado que gera importantes beneficios para alguns atores em detrimento de outros, principalmente das pessoas que se veem despojadas de suas terras e com os seus direitos diminuidos. As instituições públicas atuam como encaminhadoras dos interesses privados, sem ter em conta as demandas e experiências cidadãs, no que parece ser um processo de privatização e não de democratização da tomada de decisões.

\section{E as pessoas? Rumo a outros modelos de Co- operação Sul-Sul para a soberania alimentar}

Tratar a alimentação como um direito humano implica, como primeira medida, colocar as pessoas como sujeitos desse direito e, portanto, como protagonistas, no centro dos processos, garantindo sua participação nas diversas etapas de elaboração de políticas públicas (diagnóstico, desenho, implementação, avaliação), incluindo-se, nesse campo, a Cooperação Sul-Sul. Muitas organizações e movimentos sociais participam ativamente desse debate, não só denunciando os impactos socioambientais e territoriais negativos dos projetos atualmente em curso, como também propondo novas visões e práticas de solidariedade. Durante o Foro para a Soberania Alimentar, que aconteceu em 2007 no Sene- Fonte: Milani et al., 2014 gal, reivindicava-se que "a soberania alimentar seja considerada um di- reito humano básico, reconhecido e respeitado pelas comunidades, os povos, os Estados e as instituições internacionais." (Declaração de Nyeleni). ${ }^{18}$ Para tal, era exigida uma reforma agrária que garantisse os plenos direitos dos camponeses, a revitalização da relação entre produtores e consumidores, a garantia da sobrevivência da comunidade, a justiça econômica e social, o direito ao território, etc. Para isso, firmava-se posição contra "o controle de nossos alimentos e de nossos sistemas agrícolas por parte das empresas que colocam os lucros antes das pessoas, a saúde e o ambiente", contra "tecnologias e práticas que corroem nossa capacidade de produzir alimentos no futuro, prejudicar o meio ambiente e colocar em risco nossa saúde", e contra "modelos de desenvolvimento e indústrias extrativas que deslocam pessoas e destroem nossos ambientes e patrimônio natural.” (Declaração de Nyeleni).

Hoje, inúmeros movimentos e organi-

\section{Mapa 4 - La Via Campesina na África Países com organizações membro da rede}

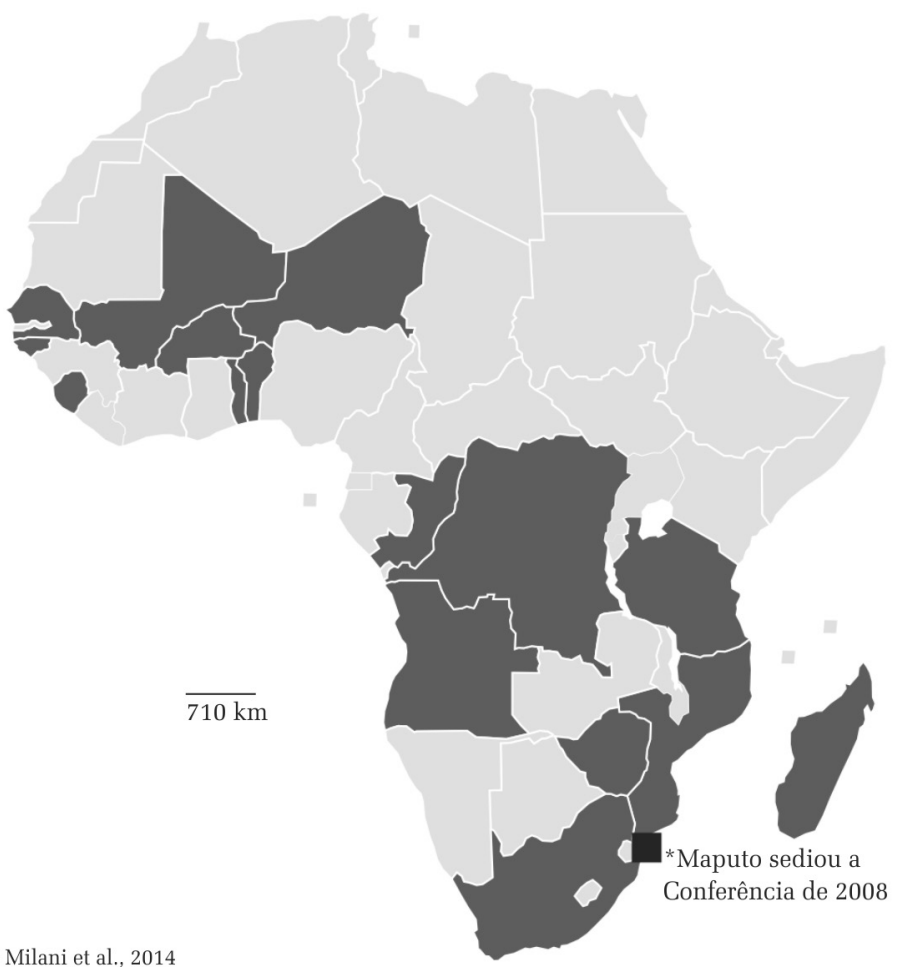

${ }^{18}$ A Declaração de Nyeleni está disponível em: http:// nyeleni.org/spip.php?article291 
zações sociais, principalmente de camponeses, ${ }^{19}$ continuam criando redes transnacionais e construindo práticas de solidariedade para defender esse direito à soberania alimentar, destacando-se o trabalho de La Via Campesina (Bringel, 2011). No campo africano, esse ativismo também é dinâmico, com demandas e práticas concentradas em áreas como a soberania alimentar, a reforma agrária, a geração de práticas de economia alternativa e o apoio à agricultura camponesa familiar e sustentável.

É interessante notar que esses movimentos sociais, para além das ações e campanhas de denuncia e advocay ${ }^{20}$ (uma das mais conhecidas sendo a que se criou em torno do ProSavana), também estão estabelecendo relações transnacionais de solidariedade, com casos interessantes no âmbito brasileiro, como a criação de brigadas e experiências formativas do Movimento dos Sem Terra (MST) do Brasil e da Via Campesina (Bringel e Vieira, 2015), de trocas organizativas entre o MST e o Movement of Landless People's Movement da África do Sul (Rosa, 2008) ou ainda de participação em projetos de cooperação

${ }^{19}$ Entre eles, podemos citar La Via Campesina, Friends of the Earth, ActionAid, Food First Action Network, Observatório do Direito à Alimentação e à Nutrição, Rede regional da sociedade civil para a segurança alimentar e nutricional na CPLP, Mecanismo da sociedade civil do comitê de Segurança Alimentar das Nações Unidas (MSC/CSA), União Nacional das Associações de Camponeses Angolanos, Landless People's Movement, a Rede de Organizações Camponesas e Produtores da Africa Ocidental, International Alliance of Residents of Socfin Bollore's Plantations,

$\bullet$ Union of Cleared Out Villages, Confederation Paysanne

○ du Congo, Concertation Nationale des Organsations Pay$\rightarrow$ sannes en Producteurs Agricoles du Congo, GRAIN, Natio-

nal Coordinating Organization for Farmers Association of Gambia, Ecumenical Association for Sustainable Agriculส ture and Rural Development, Friends of the Earth, Cadre

National de Concertation des Organisations paysannes et î de Producteurs Agricoles de la Guinée Bissau, Coalition ๓ Paysanne de Madagaskar, União Nacional de Camponeses ๓ de Moçambique, Liga Moçambicana dos Direitos Huma-

$?$ nos, Amigos da Terra Moçambique, Justiça Ambiental

$\bullet$ Moçambique, Plateforme Paysanne du Niger, Conseil Na-

- tional de Concertation et de Cooperation des Ruraux do

- Senegal, Malen Affected Land Owners Association na Ser-

จ ra Leoa, Tanzanian Network of Farmers'Groups, Coordi-

$\therefore$ nation Togolese des Organisations Paysannes, Zimbabwe

- Smallholder Farmer Forum, dentre muitos outros (Segun-

을 do pesquisa do GRISUL realizada por Henrique Fonseca Correia e Natália Pasetti).

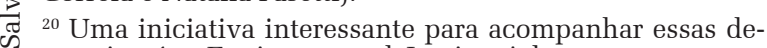

nuncias é o Environmental Justice Atlas, que apresenta

I os diversos tipos de conflitos (envolvendo, mineração e

U extrativismo, gestão de residuos, terra e biomassa, com-

- bustíveis fossies e justiça climática, gestão da água, con-

servação da biodiversidades, entre outros ), e oference in-

formações básicoas sobre cada um deles. O Atlas pode ser

consultado em: http://ejatlas.org/country
(Berrón e Brant, 2015). Trata-se de mobilizar todo um acervo de experiências que poderia ser aproveitado para gerar práticas alternativas de Cooperação Sul-Sul, mais coerente com a garantia do direito à alimentação, mais democrático, e não tão sujeito aos interesses do setor privado.

Para tal, a geração de espaços deliberativos e participativos que incluam esses atores é essencial. $\mathrm{O}$ argumento da governamentalidade e da não ingerência é utilizado para limitar a participação dos atores sociais que se apresentam como vozes disonantes. Como consequência, a CSS brasileira não tem mecanismos de participação social que permitam estabelecer diálogos com esses atores, monitorar os efeitos das práticas, ou ainda avaliar os impactos. E isso ocorre apesar da força que os movimentos e organizações sociais têm no campo da alimentação, no ambito nacional, regional e internacional. No âmbito doméstico, tanto o Conselho Nacional de Segurança Alimentar e Nutricional (CONSEA) como o Conselho Nacional de Desenvolvimento Rural Sustentável (CONDRAF) vêm tentando abrir vias de diálogo que incorporem os movimentos sociais e representantes da sociedade civil. Um passo importante, sem dúvida, seria a criação de um Conselho Nacional de Política Externa, proposto pelo Grupo de Reflexão sobre Relações Internacionais (GR-RI) como uma forma de democratizar a política externa, ao facilitar

[...] a participação de uma diversidade e pluralidade de organizações, movimentos, redes e outros fóruns que atuam no campo da política externa, contemplando os setores empresariais, organizações sindicais, movimentos sociais, organizações não governamentais, fundações partidárias, acadêmicos, instituições de estudos e centros de pesquisa, entre outros. $^{21}$

Serviria também de contrapeso à crescente privatização da política externa que se visibiliza claramente no campo da agricultura.

${ }^{21}$ GR-RI (10/09/2014): "A criação do Conselho Nacional de Política Externa fortalece o Itamaraty e consolida a inserção soberana do Brasil no Mundo", disponível em: http:// brasilnomundo.org.br/comunicados-gr-ri/a-criacao-doconselho-nacional-de-politica-externa-fortalece-o-itamaraty-e-consolida-a-insercao-soberana-do-brasil-no-mundo/\#.VmRFjYTJiAE. 


\section{CONCLUSÕES}

O campo da alimentação é um espaço em disputa entre atores e interesses muitas vezes incompatíveis. A cooperação brasileira, nesse campo, reflete essas tensões, o que termina gerando significativas contradições. O debate da coerência de políticas convertese em importante ferramenta de avaliação e visibilização desses conflitos, que podem ser encontrados na defesa de discursos opostos em um cenário internacional no qual o Brasil se apresenta, ao mesmo tempo, como defensor de um regime internacional que proteja a segurança alimentar e como potência agroexportadora que poderia servir de modelo para os países em desenvolvimento com "vocação agrícola", sem ter em conta como esse modelo está deslocando os camponeses e reorganizando as terras da produção de sementes para a alimentação em beneficio de setores extrativistas mais produtivos. Nesse sentido, não acreditamos aqui na máxima tantas vezes repetida de que "para cada problema africano existe uma solução brasileira”, na medida em que a apropriação dos processos de desenvolvimento deve ser garantida, e que, com essas soluções, são exportadas, por sua vez, grandes contradições.

É importante insistir também na necessidade de ter em conta os atores que estão, de fato, se apropriando desses procesos, e aqueles que estão sendo excluidos dessas estrategias. A África aparece muito mais como um campo de oportunidades para as empresas locais e estrangeiras do que para as pessoas que a habitam. E o mais preocupante é que a voz mais silenciada nos processos de desenvolvimento e nas práticas de cooperação está sendo a das pessoas que deveriam ser o foco dos procesos de desenvolvimento. São em número cada vez maior os que, como Achille Mbembe, filosofo camaronês, chamam a atenção sobre o fato de que essa África, vista como "a última fronteira do capistalismo", está sujeita a fortes lutas socias pela democratização, que exigem das elites inseridas nesses circuitos internacionais um novo contrato social.” (Le Monde, 2015).

A Cooperação Sul-Sul não foge dessas dinâmicas, e está recebendo, cada vez mais, críticas derivadas dessas incoerências, com a consequente perda da credibilidade. A difícil coexistência, no âmbito interno, de dois ministérios com missões e visões diferentes se traslada também nos projetos de CSS, que ora defendem a agricultura familiar, ora se inclinam para interesses de empresas transnacionais cujas ações têm impactos sociais e ambientais e podem colocar em risco a soberania alimentar dos povos. As críticas a essa CSS estão crescendo nessa área (Beghin, 2014), denunciando que o Brasil não respeita a soberania alimentar dos países; pelo contrario, incentiva práticas de expansão do agronegócio, o que resulta em: expulsão de pequenos agricultores e comunidades tradicionais de seus territórios; dependência de importação de produtos alimentares; aumento do consumo de agrotóxicos; falta de compromisso com os recursos naturais dos parceiros; primazia da economia na tomada de decisões, dentre outros. Nesse sentido, financia, por meio do BNDES, investimentos de empresas brasileiras em países africanos, dos quais resultam violação do direito humano a uma alimentação adequada, aumento de insegurança alimentar e baixa autonomia.

De fato, a crise global de alimentos está levando a uma reformulação do conceito de segurança alimentar para um enfoque mais voltado para a produção, o que incrementa o poder e a influência política do setor do agrobussiness brasileiro, reunido na Confederação da Agricultura e Pecuária do Brasil (CNA) (Milhorande, 2015). Prova disso pode ser a nomeação da Katia Abreu, antiga presidente da CNA, como Ministra de Agricultura em 2015. O enfoque brasileiro na produção de biocombustíveis transcende, assim, o discurso da cooperação para promoção de segurança alimentar e se concentra na produção de commodities agroexportadoras, gerando grande incoerência entre o discurso de cooperação para a promo- 
ção de segurança alimentar e nutricional e a conversão desse discurso para reforçar a inserção de grupos agroindustriais na região.

Além da pouca transparência das práticas de cooperação, não se estimula o envolvimento da sociedade civil, nem no Brasil, nem nos países parceiros, o que termina excluindo aqueles que sofrem as consequências dos modelos implementados. As empresas estão se beneficiando das dinâmicas de CSS, enquanto os atores sociais têm cada vez menos espaço. Sua importância nas disputas pelos sentidos do desenvolvimento e pelo controle dos impactos negativos que determinados modelos têm nas pessoas e no meio ambiente não se reflete no lugar que ocupam nas estruturas de CSS. É verdade que suas ações visibilizam incoerências que podem diminuir a imagem e a credibilidade do Brasil, mas incorporá-las ou admiti-las permitirá encontrar vias de negociação dos conflitos gerados pelos projetos de CSS, e dar, neles, uma maior centralidade à preocupação real com os direitos humanos.

Recebido para publicação em 19 de novembro de 2015 Aceiro em 20 de dezembro de 2015

\section{REFERÊNCIAS}

๑ ABREU, José F. M. de. A evolução da cooperação técnica internacional no Brasil. Mural Internacional, v. 4, n. 2, p. 3-16, 2013.

完

ACSERALD, Vitor. A Economia Política do Agronegócio ฮี no Brasil: O legado desenvolvimentista no contexto da î (Doutorado em Ciência Política) - Programa de pós?ִ graduação em Ciência Política, IESP/UERJ.

లై ANUNCIATO, Renata Oliveira. A atuação da embrapa $\therefore$ no projeto estruturante para o cotton-4: a influência da $\stackrel{0}{0}$ cooperação sul-sulna política externabrasileira. SEMINÁRIO

\& BRASILEIRO DE ESTUDOS ESTRATÉGICOS INTERNACIONAIS

- (SEBREEI), 2013. Disponível em http://www.sebreei. i⿱ eventos.dype.com.br/resources/anais/21/1370899909.

$\therefore$ ARQUIVO_RenataAnunciatoTrabalhoSebreei.pdf. Acesso em: $10.12 . \overline{2} 015$.

월

BANCO MUNDIAL. Growing Africa: Unloking the Potencial of $\geq$ Agrobussiness. Washington DC, Financial and Private Sector ஸ Development Department, 2013. Disponível em: http://wwwIi wds.worldbank.org/external/default/WDSContentServer/ WDSP/IB/2013/03/13/000350881_20130313100019/Rendered/ PDF/759720REPLACEM0mmary0pub03011013web.pdf. Acesso em: 10.12.2015.

World Development Indicators. The World Bank, 2015, Disponível em: http://data.worldbank.org/products/ wdi. Acesso em: 10.12.2015.

; IPEA (2011). Ponte sobre o Atlântico Brasil e África Subsaariana: parceria Sul-Sul para o crescimento. Brasília, 2011. Disponível em: http://www.ipea.gov.br/portal/index. php?option $=$ com content $\&$ view $=$ article \&id $=12637$. Acesso em: 10.12.20̄15.

BAYART, Jean-François. África en el espejo. Colonialidad, criminalidad y Estado, México, Fondo de Cultura Económica, 2011.

BEGHIN, Nathalie. A cooperação brasileira para o desenvolvimento internacional na área de segurança alimentar e nutricional: avanços e desafios. Onde estamos e para onde vamos? Instituto de Estudos Socioeconômicos (INESC), Brasília (DF), Agosto de 2014.

BELIK, Walter. Perspectivas para segurança alimentar e nutricional no Brasil. Saúde soc., São Paulo , v. 12, n. 1, June 2003.

GARCIA, Ana Saggioro; KATO, Karina; FONTES, Camila. A história contada pela caça ou pelo caçador? Perspectivas sobre o Brasil em Angola e Moçambique. Ed PACS. 2012. 65p. Disponível em: <http://www.pacs.org.br/ files/2013/03/Relatorio-Africa.pdf $>$ agosto 2014. Acesso em: 20.10.2015.

BERRÓN, Gonzalo; BRANT, Maria. Expertise, disputa política ou solidariedade? Variaçóes sobre o engajamento da sociedade civil brasileira na cooperação Sul-Sul. In: RAMANZINI JR., Haroldo; AYERBE, Luis F. (Org.): Política externa brasileira, cooperação sul-sul e negociações internacionais. São Paulo: Cultura Acadêmica, 2015.

BRINGEL, Breno; ECHART, Enara. Movimientos sociales, desarrollo y emancipación. In: SOTILLO, J. Á. (Org.). Antología del Desarrollo. Madrid: IUDC/La Catarata, 2015, p. 573-669.

; VIEIRA, Flávia. Movimientos internacionalistas y prácticas de cooperación sur-sur. In: Revista Española de Desarrollo y Cooperación. $\mathrm{n}^{\circ} 36$. Madrid, IUDC-UCM, 2015, p. 65-79.

- Soberanía alimentaria: la práctica de un concepto. In: Osés, P. M. (Org.). Las políticas globales importan. Madrid: IEPALA, p. 95-102, 2011.

CAISAN. Subsídios da CAISAN para a discussão sobre "cooperação internacional em segurança Alimentar e nutricional”. In: XII plenária do CONSEA. CAISAN: Brasília, 02 de dezembro de 2013.

CARMODY, Padraig. The new scramble for Africa. Cambridge: Polity Press, 2011.

CARVAlHO, Tássia C.O. A agenda ambiental na Cooperação Internacional para o Desenvolvimento: discutindo conflitos entre o Estado e a sociedade civil na Cooperação Sul-Sul oficial Brasileira, 2013. 162 p. Dissertação (Mestrado em Administração). Disponível em: http://labmundo.org/2014/wp-content/uploads/2014/06/ Carvalho_Tassia_2013.pdf. Acesso em: 10.12.2015.

CASCUDO, Câmara História da alimentação no Brasil. Belo Horizonte: Itatiaia, 2010 [1983].

CASTRO, Josué de. Geopolítica del hambre. Madrid: Ed. Guadarrama, 1972 [1951].

CASTRO, Milhorande de. Emerging Trends in Global Commodities Markets: The Role of Brazil and China in Contemporary Agrarian Transformations. In: BRICS Initiative for Critical Agrarian Studies (BICAS), 2015. Disponível em: https://www.tni.org/files/download/bicas_ working_paper_12_milhorance.pdf

CHONCHOL, Jacques. A soberania alimentar. Estud. av., São Paulo, v. 19, n. 55, Dec. 2005.

CLAPP, Jennifer. Food. Cambridge: Polity, 2012.

COMISSÃO PASTORAL DA TERRA. Conflitos no campo 
Brasil 2013. Goiânia: CPT/Centro de Documentação Dom Tomás Balduino, 2014. Disponível em: http://cptnacional. org.br/index.php/component/jdownloads/ nish/43-con itos-no-campo-brasil-publica cao/344-con itos-no-campobrasil-2013?Ite mid=23. Acesso julho, 2014.

CORREA, Marcio Lopes. Prática comentada da cooperação internacional: entre a hegemonia e a busca de autonomia. Brasília: Edição do autor, 2008.

COX, Robert. Social forces, states, and world order. In COX, R. and SINCLAIR, T. J. In: Approaches to World Order. Cambridge University Press, 1996.

ECHART Enara; GILSANZ, J.; BRINGEL, B.; SURASKY Javier. Cooperación Sur-Sur y derechos humanos: el Derecho a la Alimentación en la Cooperación argentina y brasileña desde un Enfoque Basado en los Derechos Humanos. Serie Documentos de Trabajo. v. 25, Madrid, IUDC-UCM, 2013.

. Direitos Humanos e Cooperação Sul-Sul. In: Ivo,

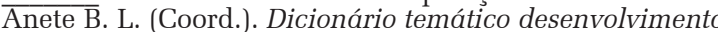
e questão social: 81 problemáticas contemporâneas. São Paulo: Annablume, 2013, p. 182-190.

ESCOBAR, Arturo. La invención del Tercer Mundo. Construcción y deconstrucción del desarrollo. Bogotá: Norma, 1996.

FAO. Diretrizes Voluntárias em apoio à realização progressiva do direito à alimentação adequada no contexto da segurança alimentar nacional. In: $127 a$ Sessão do Conselho da FAO novembro de 2004. Organização das Nações Unidas para a Alimentação e a Agricultura. Roma. Disponível em: http://www.fao.org/3/b-y7937o.pdf

- La seguridad alimentaria: información para la toma de decisiones. Guía Práctica. FAO/Unión Europea, 2011. Disponível em http://www.fao.org/docrep/014/ al936s/al936s00.pdf.

; Africa Human Development Report: Towards a Food Secure Future. Organização das Nacões Unidas para a Alimentação e a Agricultura, Roma, 2012. Disponível em: http://www.undp.org/content/dam/undp/library/ corporate/HDR/Africa\%20HDR/UNDP-Africa\%20HDR 2012-Summary-EN.pdf.

- Alimentação para todos. Cimeira Mundial da Alimentação. Organização das Nações Unidas para a Agricultura e Alimentação. Roma, 1996.

El estado de la inseguridad alimentaria en el mundo. Cumplimiento de los objetivos internacionales para 2015 en relación con el hambre: balance de los desiguales progresos. Organização das Nações Unidas para a Alimentação e a Agricultura, Roma, 2015a. Disponível em http://www.fao.org/3/aa5ef7f6-edc8-4423aae3-88bf73b3c77c/i4646s.pdf

Mapa da Fome. Organização das Nações Unidas para a Alimentação e a Agricultura, Roma, 2015b. Disponível em http://www.fao.org/hunger/es/

- Comité de Seguridad Alimentaria Mundial, $32^{\circ}$

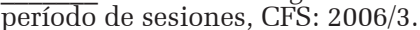

FUNDAÇÃO DOM CABRAL. Ranking FDC das multinacionais brasileiras 2013: os impactos da política externa na internacionalização de empresas brasileiras, 2013. Disponível em: http://www.fdc.org.br/ professoresepesquisa/publicacoes/Paginas/publicacaodetalhe.aspx?publicacao $=18406$.

IPEA. Cooperação Brasileira para o Desenvolvimento Internacional 2005- 2009. Brasília: Instituto de Pesquisa Econômica Aplicada / Agência Brasileira de Cooperação, 2010.

ABC. Cooperação brasileira para o desenvolvimento internacional: 2010 / Instituto de Pesquisa Econômica Aplicada, Agência Brasileira de Cooperação. Brasília, 2013. 124 p.

LE MONDE. Afrique, l'envol. Hors Série. Paris, 2015.
LLISTAR, David. Anticooperación. Interferencias NorteSur. Los problemas del Sur Global no se resuelven con más ayuda internacional. Barcelona, Icaria editorial, 2009.

MALUF et al. A cooperação brasileira em segurança alimentar e nutricional: determinantes e desafios presentes na construção da agenda internacional. Rio de Janeiro: CERESAN, 2014

MILANI, Carlos; ECHART, Enara; DUARTE, Rubens; KLEIN, Magno: Atlas da Política Externa Brasileira. Buenos Aires, CLACSO, 2014. Disponível em: http:// www.clacso.org.ar/libreria-latinoamericana/libro_detalle. php?id_libro $=927 \&$ pageNum_rs_libros $=0$ \&totalRows_rs libros $=\overline{8} 98$. Acesso em: 20.12.2015

; CARVALHO, Tássia. C. O. Cooperação Sul-Sul e Política Externa: Brasil e China no Continente Africano. In: Estudos Internacionais: revista de relações internacionais da PUC Minas, v. 1, p. 11-35, 2013.

MILLÁN ACEVEDO, N. Reflexiones para el estudio de la coherencia de políticas para el desarrollo y sus principales dimensiones. Papeles 205 y mas n. 17, Madrid, 2014.

MORAES, Maria Celina Bodin de. O conceito de dignidade humana: substrato axiológico e conteúdo normativo - ob. cit., 2003, p. 117. In: OCNUDH. Preguntas frecuentes sobre el enfoque de derechos en la cooperación para el desarrollo. Nueva York y Ginebra, 2006.

OHCHR. El derecho a la alimentación adecuada. Folleto informativo $\mathrm{N}^{\circ} 34$, Naciones Unidas/FAO, Ginebra, Junio 2010. Disponible en: http://www.ohchr.org/Documents/ Publications/FactSheet34sp.pdf

PENNA FILHO, Pio.; LESSA, Antonio Carlos. O Itamaraty e a África: As Origens da Política Africana do Brasil. In Estudos Históricos. Rio de Janeiro, v. 39, p. 57-81, 2007.

PLANALTO. Embrapa ganha mais autonomia para atuar em outros países. Março/2011. Blog do Planalto da Presidência da República. Disponível em: http://www. planalto.gov.br/ccivil_03/_ato2011-2014/2011/Lei/L12385. htm. Acesso em: $11.1 \overline{1} .20 \overline{1} 5$.

PNUD. El ascenso del Sur: Progreso humano en un mundo diverso. Informe sobre Desarrollo Humano Nueva York, PNUD, 2013. Disponível em http://hdr.undp.org/es/ content/informe-sobre-desarrollo-humano-2013

. Towards a food secure future. African Human Development Report 2012. Nueva York: Programa de Naciones Unidas para el Desarrollo, 2012. Disponível em: http://www.undp.org/content/dam/undp/library/ corporate/HDR/Africa\%20HDR/UNDP-Africa\%20HDR2012-Summary-EN.pdf

ROSA, Marcelo. Estado e ações coletivas na África do Sul e no Brasil: por uma sociologia contemporânea dos países. In: Sociologias, Porto Alegre, ano 10, no 20, jul./dez. 2008, p. 292-318.

SABOURIN, Eric. Que política pública para a agricultura familiar no segundo governo Lula?. Soc. estado, Brasília, v. 22, n. 3, p. 715-751, dez. 2007.

SEN, Amartya: Desarrollo y libertad. Editorial Planeta, Madrid, 2000

SOTILLO, José Ángel (Org.): Antología del Desarrollo. Madrid: IUDC/La Catarata, 2015.

VEIGA, Pedro; RIOS, Sandra. O Brasil como ator econômico na África: a necessidade de uma estratégia. Centro de Estudos de Integração e Desenvolvimento (CINDES), 2015. Disponível em: www.cindesbrasil.org. Acesso em: 18.11.2015.

VIEITAS, Deborah; ABOIM, Isabel. África: oportunidades para empresas brasileiras. In: Revista Brasileira de Comércio Exterior, n. 116, p. 20-33, jul-set. 2013. Disponível em: http://www.funcex.org.br/publicacoes/rbce/material/ rbce/116 DV IA.pdf. Acesso em: 20.12.2015. 


\section{SOUTH-SOUTH COOPERATION BETWEEN BRAZIL AND AFRICA IN THE FIELD OF FOOD: a policy that is coherent with development?}

\author{
Enara Echart Muñoz \\ Tássia Camila de Oliveira Carvalho
}

Brazil actively participates in the international cooperation and development in many different areas, but with special emphasis on agriculture and food. Brazil is an international reference in these areas due to the relative success of internal assistance programs (Bolsa Família, Fome Zero, etc.) and to the possibility of transferring these experiences to other countries. On the other hand, it is a key sector for Brazilian companies, for which agribusiness is one of the bases for their accumulation of capital. Food is, then, at the same time, a basic right that must be secured and protected and a commodity that can be exchanged at high profits in the commodities market. The tensions created around these two views are the reason for this article, which analyzed the practices of the South-South Cooperation with African countries in the field of food with an approach towards the coherence of policies with development.

Keywords: South-South Cooperation, Brazil, Africa, Food, Policies Coherence.

\section{COOPERATION SUD-SUD ENTRE LE BRÉSIL ET L'AFRIQUE DANS LE DOMAINE DE \\ L'ALIMENTATION: une politique cohérente avec le développement?}

\author{
Enara Echart Muñoz \\ Tássia Camila de Oliveira Carvalho
}

Le Brésil participe activement dans la coopération internationale pour le développement dans différents domaines, mais avec un accent particulier sur l'agriculture et l'alimentation. Dans cette matière, le Brésil se présente comme une référence internationale en raison du succès relatif des programmes internes (Bolsa Familia, Faim zéro, etc.) et la possibilité de transfert externe de ces expériences. D’autre part, c’est un secteur clé pour les entreprises brésiliennes, qui ont dans l'agroindustrie l'une des bases de leur accumulation de capital. L'alimentation est ainsi à la fois un droit fondamental qui doit être garanti et protégé, et une marchandise qui peut être échangée avec des profits élevés sur le marché des matières premières. Les tensions engendrées autour de ces deux visions motivent cet article, qui analyse les pratiques de coopération Sud-Sud entre le Brésil et les pays africains dans le domaine de l'alimentation à partir d'une approche de cohérence des politiques avec le développement.

Mots CLÉs: Coopération Sud-Sud, Afrique, Alimentation, cohérence des politiques Internacionais e Sul Global). Pesquisadora do LABMUNDO (IESP-UERJ) e do Instituto Universitario de Desarrollo y Cooperación da Universidad Complutense de Madri. Seus principais âmbitos de atuação são Relações Internacionais; Cooperação para o Desenvolvimento; Direitos Humanos; Movimentos Sociais e Sociedade Civil, Migrações e Desenvolvimento, África, América Latina. Publicações recentes: Cooperación Sur-Sur y derechos humanos: el derecho a la alimentación en la cooperación brasileña y argentina. Revista Española de Desarrollo y Cooperación, v. 32, p. 98-117, 2013; Does the South challenge the Geopolitics of International Development Cooperation?. Geopolitica(s): revista de estudios sobre espacio y poder, v. 4-1, p. 35-41, 2013; Dez anos de Seattle, o movimento antiglobalização e a ação coletiva transnacional. Ciências Sociais Unisinos, v. 46, p. 28-35, 2010.

Tássia Camila de Oliveira Carvalho - Doutoranda em Ciência Política pelo IESP/UERJ e pesquisadora do Labmundo-Rio (IESP/UERJ) com bolsa da FAPERJ. Desenvolve pesquisa nas temáticas de Ecologia Política, Cooperação Sul-Sul e Segurança Alimentar e Nutricional. 